\title{
Perbandingan Bupivakain Infiltrasi Subkutis dengan Kombinasi Bupivakain Intramuskular Rectus Abdominis dan Subkutis terhadap Mulai Pemberian dan Kebutuhan Analgetik Rescue Pascaoperasi Laparatomi Ginekologi
}

\author{
Said Badrul Falah, Ezra Oktaliansah, Ike Sri Redjeki \\ Departemen Anestesiologi dan Terapi Intensif \\ Fakultas Kedokteran Universitas Padjadjaran/Rumah Sakit Dr. Hasan Sadikin Bandung
}

\begin{abstract}
Abstrak
Penanganan nyeri pascaoperatif kurang baik akan membuat pasien trauma terhadap pembedahan dan menimbulkan komplikasi lain. Penelitian ini bertujuan membandingkan pemberian bupivakain secara kombinasi intramuskular (IMSK) dan subkutis dengan pemberian subkutis saja (SK) terhadap mulai pemberian dan kebutuhan analgetik rescue pascaoperasi laparatomi ginekologi. Penelitian dilakukan di Rumah Sakit Dr. Hasan Sadikin Bandung bulan September-Desember 2014 terhadap 46 wanita (18-60 tahun) status fisik American Society of Anesthesiology (ASA) I-II yang menjalani pembedahan laparatomi ginekologi secara uji acak terkontrol buta ganda dalam anestesi umum. Pasien dibagi menjadi dua, yaitu 23 orang menerima bupivakain kombinasi pada otot rectus abdominis dan subkutis dan 23 orang menerima bupivakain infiltrasi subkutis saja. Penilaian skala nyeri menggunakan nilai numeric rating scale dan dilakukan pencatatan pada jam ke-1, 2, 3, 4, 5, 6, 8, 12, dan 24 pascaoperasi. Pemberian analgetik rescue dilakukan bila nilai NRS $\geq 4$. Data dianalisis dengan uji-t, chi-kuadrat, dan Mann-Whitney. Pada penelitian ini ditemukan waktu mulai pemberian analgetik rescue pada kelompok IMSK lebih lama $(p<0,01)$ dan kebutuhan analgetik tambahan dalam 24 jam lebih sedikit $(\mathrm{p}<0,01)$ dibanding dengan kelompok SK. Simpulan, pemberian bupivakain secara kombinasi intramuskular dan subkutis lebih baik dibanding dengan pemberian subkutis saja terhadap waktu mulai pemberian dan kebutuhan analgetik rescue dalam 24 jam pascaoperasi laparatomi ginekologi.
\end{abstract}

Kata kunci: Bupivakain, numeric rating scale, otot rectus abdominis

\section{Comparison between Subcutis Bupivacaine Infiltration and Combined Intramuscular Rectus Abdominal and Subcutis Bupivacaine to on Total Need of Rescue Analgesics after Gynecologic Laparatomy}

\begin{abstract}
Inappropriate management of post-operative pain will cause trauma to the patient regarding the surgical experience and may possibly cause other complications. This study aimed to compare the administration of intramuscular and subcutis bupivacaine to subcutis only bupivacaine on the start and need for rescue analgesics. This study was conducted in Dr. Hasan Sadikin General Hospital Bandung during the period of September-December 2014 on 46 females aged 18-60 years old with American Society of Anesthesiology (ASA) I-II who underwent gynecological laparatomy under general anesthesia. This was a randomized controlled study. Patients were dividedinto two groups of 23 patients with the first group received combination infiltration and the other received only subcutis administration. The pain scale used was the numerical rating scale measured $-1,2,3,4,5,6,8,12$, and 24 hours after surgery. Rescue analgesics was given if NRS was more than 4. Data were analyzed using t-test, chi-square test, and Mann-Whitney test. Observations were performed on time span until there was a need for analgesics for the first time and additional analgesic needed in 24 hours. In this study, the time span until the first dose analgesics was needed was longer and the amount of required analgesics during 24 hours was lower in the combination group $(\mathrm{p}<0.01)$. In conclusion, the combination strategy has a better outcome regarding the time span to the start of rescue analgetic and 24 hours analgesic needs.
\end{abstract}

Key words: Bupivacaine, numeric rating scale, abdominal recti muscle

Korespondensi: Said Badrul Falah, dr., SpAn, Departemen Anestesiologi dan Terapi Intensif Faklutas Kedokteran Universitas Padjadjaran/Rumah Sakit Dr. Hasan Sadikin Bandung, Jl. Pasteur No. 38 Bandung, Mobile 08170274063, Email saidunpad2001@yahoo.com 


\section{Pendahuluan}

Nyeri pascaoperatif yang tidak ditangani secara adekuat menyebabkan efek samping fisiologis yang dapat meningkatkan angka morbiditas dan juga mortalitas sehingga memperlambat waktu penyembuhan serta aktivitas kembali ke normal. Penatalaksanaan nyeri pascaoperatif yang kurang baik akan mengakibatkan pasien trauma terhadap pembedahan serta berperan menimbulkan komplikasi lainnya. Selain itu, hal ini juga akan meningkatkan insiden nyeri kronik pascaoperasi. ${ }^{1}$

Operasi abdominal termasuk di dalamnya operasi ginekologi merupakan jenis operasi dengan skala nyeri pascabedah yang cukup tinggi sehingga operasi ini membutuhkan penanganan nyeri pascabedah yang lebih baik. Nyeri pascaoperasi histerektomi abdominal termasuk nyeri hebat dengan skala nyeri 7-8 dari skala maksimal $10 .^{2}$

Penggunaan teknik blokade saraf perifer meningkat tidak hanya sebagai anestesia tunggal yang bertujuan untuk memfasilitasi pembedahan, namun digunakan juga bersama anestesia umum, sedasi, analgesia preoperatif, dan juga pascaoperatif. Perkembangan jarum blokade saraf perifer, obat-obat anestesia lokal yang lebih aman, dan kateter perineural telah membawa perubahan dalam anestesi regional yang tidak terfokus hanya pada tindakan anestesia untuk fasilitasi pembedahan, namun telah banyak pula digunakan sebagai analgetik pascaoperasi. $^{3}$

Pada saat ini pemakaian anestesia regional semakin berkembang dan meluas di seluruh dunia. Anestesia regional dapat memblokade organ spesifik yang dituju, memiliki durasi yang lama, serta dapat memberikan analgesia dan anestesia yang efektif. Selain itu, anestesi regional juga dapat mengurangi morbiditas, mortalitas, dan dapat dipakai untuk prosedur operasi besar. Berkurangnya nyeri dan efek samping (mual serta muntah) pascaoperasi dapat meningkatkan kepuasan serta mobilisasi yang lebih awal sehingga dapat menghemat biaya perawatan. ${ }^{4,5}$

Penggunaan bupivakain sebagai analgetik pascaoperasi seksio sesarea telah ditelititi pada 100 pasien yang menjalani seksio sesarea dengan jenis sayatan mediana. Penyuntikan bupivakain 0,5\% langsung pada luka operasi, yaitu pada peritonium, otot, subkutis, dan kutis mengurangi skala nyeri pascaoperasi seksio sesarea dan juga mengurangi analgetik opioid sistemik dibanding dengan pemberian tramadol sistemik saja. ${ }^{6}$

Penelitian terhadap pasien yang menjalani perkutaneus nefrolitotomi menyimpulkan bahwa infiltrasi bupivakain $0,25 \%$ di daerah kulit, subkutan, saluran nefrostomi, dan kapsul ginjal secara signifikan menurunkan visual analog scale (VAS), memperpanjang analgesia, dan mengurangi konsumsi analgetik rescue dalam 24 jam pertama. ${ }^{7}$

Penelitian terhadap pasien yang menjalani operasi seksio sesarea dengan teknik regional anestesia yang mendapatkan infiltrasi 20 mL lidokain 1\% dengan 1:100.000 adrenalin menunjukkan bahwa tempat infiltrasi pada luka operasi, yaitu subkutis, intramuskular, dan subkutis ditambah intramuskular secara signifikan dan efektif dapat mengurangi nyeri dan kebutuhan analgetik rescue bila dibanding dengan plasebo. ${ }^{8}$

Hasil penelitian lain menunjukkan bahwa infiltrasi selektif terhadap otot rektus pada luka operasi tanpa jaringan fasia dan subkutis di sekitarnya dengan $0,5 \%$ bupivakain signifikan mengurangi nilai nyeri serta kebutuhan morfin per jam selama 2 jam pascaoperasi dan total kebutuhan morfin 6 jam pascaoperasi pada histerektomi per abdominal. ${ }^{9}$

Tujuan penelitian ini adalah mengetahui perbedaan lama waktu pemberian analgetik rescue dan jumlah kebutuhan analgetik rescue pada kombinasi bupivakain $0,25 \%$ secara intramuskular rectus abdominis dan infiltrasi subkutis dengan pemberian infiltrasi subkutis saja pascaoperasi laparatomi ginekologi.

\section{Subjek dan Metode}

Penelitian ini adalah penelitian eksperimental dengan melakukan uji acak terkontrol buta ganda. Pemilihan subjek berdasarkan kriteria inklusi, yaitu semua pasien yang dirawat di Rumah Sakit Dr. Hasan Sadikin Bandung yang 
akan menjalani operasi laparatomi ginekologi elektif dengan anestesia umum, status fisik American Society of Anesthesiology (ASA) kelas I-II, usia 18-60 tahun, insisi mediana. Kriteria eksklusi adalah riwayat alergi terhadap obatobatan yang dipergunakan dalam penelitian, mendapatkan analgetik dalam 24 jam sebelum operasi, dan kelainan kulit di tempat suntikan.

Besar sampel ditentukan mempergunakan rumus perbedaan proporsi efektivitas tindakan dengan memilih tingkat kepercayaan 95\% dan besarnya uji kekuatan 80\%. Didapatkan jumlah sampel adalah 23 untuk tiap kelompok perlakuan dan jumlah seluruh sampel adalah 46 orang.

Setelah mendapat persetujuan Komite Etik Penelitian Kesehatan Fakultas Kedokteran Universitas Padjadjaran/Rumah Sakit Dr. Hasan Sadikin Bandung, diberikan penjelasan mengenai alur penelitian kepada subjek yang diikuti dengan menandatangani persetujuan (imformed consent), dijelaskan pula tentang tata cara penilaian numeric rating scale (NRS). Dilakukan randomisasi pada sampel menjadi dua kelompok perlakuan dengan tabel bilangan random. Pasien dipasang kateter intravena, alat pengukur tekanan darah noninvasif, dan pulse oksimetri di kamar operasi.

Semua pasien mendapatkan teknik induksi anestesia standar dengan propofol $2-2,5 \mathrm{mg} /$ $\mathrm{kgBB}$, fentanil $2 \mu \mathrm{g} / \mathrm{kgBB}$ dan atrakurium 0,5 $\mathrm{mg} / \mathrm{kgBB}$ secara intravena, setelah 3 menit dilakukan laringoskopi intubasi. Pemeliharaan anestesia dilakukan dengan mempergunakan isofluran $1-2,5$ volume $\%$ dan $\mathrm{N}_{2} \mathrm{O}: \mathrm{O}_{2} 50 \%$.

Dalam keadaan steril disiapkan preparat dalam spuit $10 \mathrm{~mL}$ dua buah untuk pemberian secara intramuskular dan infiltrasi. Diambil bupivakain $0,25 \%$ sebanyak $10 \mathrm{~mL}$ pada spuit masing-masing.

Setelah peritonium ditutup, pada kelompok IMSK diberikan infiltrasi anestetik pada otot rectus abdominis dengan bupivakain 0,25\% $10 \mathrm{~mL}$ dan juga lapisan subkutis $10 \mathrm{~mL}$. Pada kelompok SK dilakukan infiltrasi bupivakain 0,25\% $20 \mathrm{~mL}$ pada subkutis saja saat kulit akan ditutup. Pada kedua kelompok diberikan ketorolak intravena $0,5 \mathrm{mg} / \mathrm{kgBB} 30$ menit sebelum operasi selesai dan dilanjutkan tiap 8 jam.

Setelah operasi selesai, pasien dipindahkan ke ruang pemulihan dan dilakukan observasi

Tabel 1 Nilai rata-rata dan Simpang Baku Karakteristik Umum Subjek Penelitian pada Kelompok Intramuskular dengan Subkutis dan Subkutis

\begin{tabular}{lccc}
\hline \multirow{2}{*}{ Variabel } & \multicolumn{2}{c}{ Kelompok } & \multirow{2}{*}{ Nilai $\mathbf{~ p}^{*}$} \\
\cline { 2 - 3 } & IMSK (n=23) & SK (n=23) & 0,399 \\
\hline Usia (tahun; mean \pm SD) & $37,6 \pm 10,3$ & $40,0 \pm 8,6$ & 0,838 \\
BB (kg; mean \pm SD) & $50 \pm 3,6$ & $52 \pm 3,2$ & 0,612 \\
BMI (kg/m²; mean \pm SD) & $21,3 \pm 1,5$ & $21,1 \pm 1,4$ & 0,476 \\
Lama operasi & $126,3 \pm 26,6$ & $131,1 \pm 23,9$ & 0,193 \\
(menit; mean \pm SD) & & & \\
Pendidikan & 0 & 2 & \\
SD & 3 & 7 & \\
SMP & 19 & 13 & \\
SMA & 1 & 1 & \\
Sarjana & 11 & & \\
Jenis operasi & 10 & 8 & \\
Histerektomi & 2 & 2 & \\
Salfingo-ovarektomi & & & \\
Miomektomi & & & \\
\hline
\end{tabular}

Keterangan: bermakna ( $\mathrm{p}<0,05)$, nilai p dihitung berdasarkan uji-t (usia, BMI), chi-kuadrat (pendidikan, jenis operasi) dan Mann-Whitney (lama operasi) 
selama 24 jam oleh peneliti dan paramedis di ruangan. Penilaian skala nyeri pascaoperasi dilakukan dengan menggunakan NRS setiap jam selama 6 jam pertama, jam ke-8, 12, dan
24. Bila NRS $\geq 4$ maka diberikan analgetik penyelamatan denganmemakai petidin $25 \mathrm{mg}$ intravena. Pencatatan skor nyeri, laju nadi, tekanan darah, laju napas, efek samping, dan

Tabel 2 Hasil Pengukuran Nilai NRS pada Berbagai Waktu Pengukuran

\begin{tabular}{|c|c|c|c|c|}
\hline \multirow{2}{*}{ Waktu Pengukuran } & \multicolumn{3}{|c|}{ Kelompok } & \multirow{2}{*}{ Nilai p } \\
\hline & NRS & IMSK $(n=23)$ & SK $(n=23)$ & \\
\hline \multirow[t]{2}{*}{ T0 } & 0 & 23 & 23 & \\
\hline & 0 & 13 & 11 & \\
\hline \multirow[t]{4}{*}{$\mathrm{T} 1$} & 1 & 8 & 9 & 0,808 \\
\hline & 2 & 2 & 3 & \\
\hline & 0 & 6 & - & \\
\hline & 1 & 15 & 8 & \\
\hline \multirow[t]{5}{*}{$\mathrm{T} 2$} & 2 & 2 & 8 & 0,001 \\
\hline & 3 & - & 6 & \\
\hline & 4 & - & 1 & \\
\hline & 0 & 5 & 1 & \\
\hline & 1 & 10 & 5 & \\
\hline \multirow{5}{*}{$\mathrm{T} 3$} & 2 & 8 & 7 & 0,006 \\
\hline & 3 & - & 5 & \\
\hline & 4 & - & 5 & \\
\hline & 0 & 3 & 1 & \\
\hline & 1 & 13 & 1 & \\
\hline \multirow{5}{*}{$\mathrm{T} 4$} & 2 & 5 & 9 & $<0,001$ \\
\hline & 3 & 2 & 5 & \\
\hline & 4 & - & 7 & \\
\hline & 0 & 1 & - & \\
\hline & 1 & 10 & 2 & \\
\hline \multirow[t]{5}{*}{$\mathrm{T} 5$} & 2 & 10 & 11 & 0,011 \\
\hline & 3 & 2 & 4 & \\
\hline & 4 & - & 6 & \\
\hline & 0 & 1 & - & \\
\hline & 1 & 6 & 2 & \\
\hline \multirow[t]{5}{*}{ T6 } & 2 & 10 & 9 & 0,282 \\
\hline & 3 & 3 & 6 & \\
\hline & 4 & 3 & 6 & \\
\hline & 0 & 1 & 1 & \\
\hline & 1 & 9 & 5 & \\
\hline \multirow[t]{4}{*}{$\mathrm{T} 8$} & 2 & 4 & 8 & 0,317 \\
\hline & 3 & - & 2 & \\
\hline & 4 & 9 & 7 & \\
\hline & 0 & 3 & 1 & \\
\hline \multirow[t]{3}{*}{$\mathrm{T} 12$} & 1 & 17 & 16 & 0,362 \\
\hline & 2 & 3 & 6 & \\
\hline & 0 & & 2 & \\
\hline \multirow[t]{2}{*}{$\mathrm{T} 24$} & 1 & 18 & 16 & 0,734 \\
\hline & 2 & 3 & 5 & \\
\hline
\end{tabular}

Keterangan: T0=saat masuk RR, T1=jam ke-1, T2=jam ke-2, dan seterusnya. Nilai p dihitung berdasarkan uji chi-kuadrat. Nilai $p$ bermakna $(\mathrm{p}<0,05)$ 
Tabel 3 Perbandingan Lama Waktu Dibutuhkan Rescue Analgetic Pertama

\begin{tabular}{ccc}
\hline $\begin{array}{c}\text { Waktu } \\
\text { Dibutuhan } \\
\text { Rescue } \\
\text { Pertama (Jam) }\end{array}$ & IMSK (n=23) & SK (n=23) \\
\cline { 2 - 3 } & - & 1 \\
2 & - & 5 \\
3 & - & 7 \\
4 & - & 6 \\
5 & 3 & 3 \\
6 & 9 & 1 \\
8 & 11 & - \\
\hline
\end{tabular}

Keterangan: $\chi_{\text {trend }}^{2}=36,40 ; p<0,001$

penggunaan total petidin tambahan dilakukan selama 24 jam. Penggunaan petidin dihentikan bila laju napas $<12 \mathrm{x} /$ menit, saturasi oksigen $<95 \%$, atau timbul efek samping yang serius akibat pemakaian petidin. Apabila terjadi mual muntah diterapi dengan onadansetron $4 \mathrm{mg}$ secara intravena.

Analisis statistik penelitian menggunakan uji-t, chi-kuadrat, dengan tingkat kepercayaan $95 \%$ dan dianggap bermakna bila $\mathrm{p}<0,05$. Data disajikan dalam rata-rata (mean) dan dianalisis dengan program statistical product and service solution (SPSS) 13,0 for windows.

\section{Hasil}

Hasil analisis statistik pada derajat kepercayaan 95\% menunjukkan tidak terdapat perbedaan bermakna pada karakteristik usia, body mass index (BMI), tingkat pendidikan, lama operasi, dan jenis operasi antara kelompok IMSK dan kelompok SK ( $p>0,05$; Tabel 1).

Terdapat perbedaan NRS yang bermakna antara kelompok IMSK dan kelompok SK pada pengukuran jam ke-2, $-3,-4$, dan $-5(\mathrm{p} \leq 0,05)$. Namun, tidak terdapat perbedaan bermakna pada nilai NRS antara pemberian bupivakain kombinasi intramuskular dan subkutis pada pengukuran jam pertama dan pengukuran di atas jam ke-5 pascaoperasi ( $p>0,05$; Tabel 2).

Waktu dibutuhkan analgetik rescue pertama pada kelompok IMSK paling banyak pada jam ke-8 dan terdapat 11 dari 23 subjek yang tidak
Tabel 4 Perbandingan Kebutuhan Rescue Analgetic

\begin{tabular}{ccc}
\hline \multirow{2}{*}{$\begin{array}{c}\text { Kebutuhan } \\
\text { Rescue }(\mathbf{m g})\end{array}$} & \multicolumn{2}{c}{ Kelompok } \\
\cline { 2 - 3 } & $\begin{array}{c}\text { IMSK } \\
(\mathbf{n = 2 3 )}\end{array}$ & $\begin{array}{c}\text { SK } \\
(\mathbf{n = 2 3 )})\end{array}$ \\
\hline 0 & 11 & 0 \\
25 & 12 & 14 \\
50 & 0 & 9 \\
\hline
\end{tabular}

Keterangan: $\chi^{2}=20,154 ; p<0,001$

diberikan analgetik rescue, sedangkan pada kelompok SK terdapat 1 dari 23 subjek yang membutuhkan analgetik rescue pada jam ke-2 dan yang paling banyak pada jam ke- 4 dan ke-5. Terdapat perbedaan yang bermakna pada lama waktu dibutuhkan analgetik rescue pertama pada kedua kelompok $(\mathrm{p}<0,05$; Tabel $3)$.

Jumlah kebutuhan petidin pada kelompok IMSK adalah 25 mg pada 12 dari 23 subjek dan sisanya 11 dari 23 subjek tidak membutuhkan tambahan petidin, sedangkan pada kelompok SK semua diberikan analgetik rescue petidin $25 \mathrm{mg}$ pada 14 dari 23 subjek dan $50 \mathrm{mg}$ pada 9 dari 23 subjek. Terdapat perbedaan yang bermakna kebutuhan analgetik rescue antara kedua kelompok $(\mathrm{p}<0,05$; Tabel 4).

\section{Pembahasan}

Berdasarkan nilai rata-rata dan simpangan baku karakteristik umum subjek penelitian pada tiap kelompok (Tabel 1), terlihat bahwa usia, berat badan, body mass index (BMI), lama operasi, dan pendidikan pada kedua kelompok perlakuan tidak menunjukkan perbedaan yang bermakna sehingga pasien secara statistika adalah homogen dan layak dibandingkan.

Jenis operasi juga tidak berbeda pada semua subjek penelitian, yaitu operasi laparatomi ginekologi (histerektomi dengan atau tanpa disertai salpingektomi, salpingektomi, dan miomektomi). Operasi abdominal termasuk di dalamnya operasi ginekologi merupakan jenis operasi dengan skala nyeri pascabedah cukup tinggi sehingga membutuhkan penanganan nyeri pascabedah yang lebih baik. $^{2}$

Untuk dapat melakukan penatalaksanaan 
nyeri yang tepat serta mengetahui kualitas pengurangan nyeri yang telah kita lakukan maka harus dilakukan pengukuran derajat nyeri. Pengukuran terhadap derajat nyeri ini harus dilakukan secara berkala dan berulang sehingga membantu kita mengetahui adekuat atau tidak analgetik yang telah kita berikan, oleh karena itu waktu pengukuran dilakukan selama 24 jam. Pada penelitian ini, pengukuran derajat nyeri dilakukan menggunakan numeric rating scale (NRS) pada saat pasien berbaring yang dimulai saat pasien masuk ke ruang pemulihan.

Penilaian NRS pada kelompok bupivakain kombinasi injeksi intramuskular dan subkutis dibanding dengan kelompok subkutis pada jam ke-2, -3, -4, dan -5 mempunyai nilai NRS lebih rendah dengan perbedaan yang bermakna $(p<0,05)$. Hasil penelitian ini sesuai dengan penelitian sebelumnya oleh Tan dkk. ${ }^{9}$ yang menyatakan bahwa pemberian bupivakain intramuskular pada otot rektus abdominis mengurangi derajat nyeri dan kebutuhan total morfin selama 6 jam pascaoperasi hiterektomi abdominal.

Penilaian lama waktu dibutuhkan analgetik rescue pertama kali (Tabel 3) pada kelompok bupivakain kombinasi intramuskular dan subkutis lebih lama bila dibanding dengan kelompok subkutis saja $(\mathrm{p}<0,001)$. Pemberian analgetik rescue ini bertujuan menghilangkan nyeri yang tidak tetangani dengan analgetik yang ada. Pada penelitian ini rescue analgetik petidin diberikan $25 \mathrm{mg}$ bolus intravena setiap kali pemberian. Dosis tersebut akan diulang sampai pasien merasa nyaman.

Jumlah kebutuhan petidin pada kelompok bupivakain kombinasi intramuskular dan subkutis lebih sedikit bila dibanding dengan kelompok subkutis $(\mathrm{p}<0,001)$. Penanganan nyeri pascaoperasi adalah komponen penting dalam perawatan perioperatif. Teknik anestesi lokal lebih efektif dibanding dengan analgetik sistemik bila ditinjau dari penggunaan dan cara pemberiannya. Sampai saat ini penelitian difokuskan pada blok neuraksial sentral dan saraf perifer. Meskipun hal ini sangat efektif digunakan terutama pada saat pembedahan toraks dan abdominal, namun karena angka kegagalan tinggi, risiko infeksi, dan hematom spinal maka pemilihan teknik blokade tertentu yang paling sederhana, paling aman, dan paling efektif dapat digunakan bila memungkinkan. Oleh karena itu, pemberian langsung anestesia lokal pada lapisan yang teridentifikasi selama pembedahan dapat dipertimbangkan oleh dokter bedah dan dokter anestesi. ${ }^{10}$

Salah satu komponen nyeri yang dirasakan oleh pasien setelah operasi abdomen adalah sayatan kulit dan juga penarikan otot dinding abdomen. Pendekatan analgesia pascaoperasi setelah sayatan abdominal dilakukan dengan blokade saraf sensoris pada dinding abdomen anterior. $^{11}$

Teknik infiltrasi memakai anestetik lokal menghasilkan efek analgetik melalui beberapa mekanisme, yaitu menghambat reseptor nosisepsi aferen sehingga mencegah transmisi impuls nyeri, menghambat pelepasan mediator inflamasi, dan juga mengurangi pembentukan radikal bebas serta edema. ${ }^{12}$ Obat anestesi lokal bekerja dengan menghambat kanal natrium sehingga mencegah transmisi impuls saraf sepanjang serabut aksonal yang merupakan efek lokal pada daerah penyuntikan. ${ }^{3}$

Pemberian bupivakain intramuskular pada otot rektus abdominis mengurangi kebutuhan analgetik yang kemungkinan disebabkan oleh beberapa hal, yaitu pertama dapat mengurangi spasme otot yang disebabkan oleh tarikan saat operasi, kedua bupivakain yang disuntikkan berdifusi ke dalam otot rektus yang dapat memblok nervus cutaneous anterior dinding perut, dan ketiga bupivakain berdifusi ke posterior ke dalam kantung rektus posterior di atas linea arcuata dan memblokade nervus cutaneous anterior seperti pada rectus sheath block. $^{9}$

\section{Simpulan}

Berdasarkan hasil penelitian dan pembahasan disimpulkanbahwapemberian obatbupivakain $0,25 \%$ secara kombinasi intramuskular rectus abdominis dan infiltrasi subkutis pada saat intraoperatif membutuhkan waktu rescue analgetic yang lebih lama dan kebutuhan rescue analgetic pertama yang lebih rendah 
dibanding dengan kelompok yang hanya mendapatkan infiltrasi subkutis pascaoperasi laparatomi ginekologi.

Pemberianbupivakainsecaraintramuskular dan subkutis dapat direkomendasikan sebagai analgetik pascaoperasi yang merupakan cara sederhana, mudah, aman, dan efektif . Cara ini dapat diberikan pada pasien yang menjalani pembedahan laparatomi ginekologi. Faktorfaktor yang memengaruhi jumlah kebutuhan analgetik opioid pascaoperasi terjadi melalui berbagai kondisi, oleh karena itu sebaiknya dilakukan penelitian lanjutan mengenai dosis, tempat penyuntikan, dan jenis operasi yang berbeda.

\section{Daftar Pustaka}

1. Macres SM, Moore PG, Fishman SM. Acute pain management. Dalam: Barash PG, Cullen BF, Soelting RK, penyunting. Clinical anesthesia. Edisi ke-6. Philadelphia: Lippincot William \& Wilkins; 2009. hlm. 1405-40.

2. Yap O, Husain A, Schmiesing C. Gynecologic oncology. Dalam: Jaffe R, Samuels S, penyunting. Anesthesiologist's manual of surgical procedures. Edisi ke-4. Philadelphia: Lippincot Williams \& Wilkins; 2009. hlm. 745-82.

3. Morgan GE, Maged MS, Murray MJ. Peripheral nerve blocks. Dalam: Morgan GE, penyunting. Clinical anesthesiology. Edisi ke-4. New York: McGraw-Hill Companies; 2006. hlm. 324-5.

4. Rukewe A, Fatiregun A. The use of regional anesthesia by anesthesiologists in Nigeria. Anesth Analg. 2010;110(1):243-4.

5. Tsui BC, Rosenquist RW. Peripheral nerve blockade. Dalam: Barash PG, Cullen $\mathrm{BF}$, Stoelting RK, penyunting. Clinical anesthesia. Edisi ke-6. Philadelphia: Lippincot William \& Wilkins; 2009. hlm. 718-45.

6. Amin S, Tahir S. Impact of bupivacaine infiltration of postoperative wound on parenteral narcotic analgesic requirement for pain. Pakistan J Surg. 2010 OctoberDecember;15(4):177-81.

7. Parikh GP, Shah VR, Modi MP, Chauhan NC. The analgesic efficacy of peritubal infiltration of $0.25 \%$ bupivacaine in percutaneus neprolithotomy, a prospective randomized study. J Anesth Clin Pharmacol. 2011;27(4):481-4.

8. Navali N, Fouladi RF, Nikpour MA. A comparison of post-incisional subcutaneous, intramuscular, and subcutaneous plus intramuscular infiltration of lidocaine in post caesarean section pain control. S Afr J OG. 2013;19(1):8-12.

9. Tan $\mathrm{CH}$, Kun $\mathrm{KY}$, Onsiong $\mathrm{MK}$, Chan $\mathrm{MK}$, Tai CM. Postincisional local anaesthetic infiltration of the rectus muscle decreases early pain and morphine consumption after abdominal hysterectomy. Acute Pain. 2002;4(1):49-52.

10. Scott NB. Wound infiltration for surgery. Anaesthesia. 2010;89(1):67-75.

11. John GM, Brian OD, Anne H, Camilus P, John GL. The analgesic efficacy of transversus abdominis plane block after abdominal surgery: a prospective randomized controlled. Anesth Analg. 2007;104:1937.

12. Hahnenkamp K, Theilmaier G, Allen $\mathrm{H}$, Hoenemann C. The effect of local anesthetic on perioperative coagulation, inflammatory and microcirculation. Anesth Analg. 2002;23:1441-7. 